\title{
Effect of cisapride on delayed gastric emptying in gastro-oesophageal reflux disease
}

\author{
G J Maddern, G G Jamieson, J C Myers, P J Collins
}

\begin{abstract}
Some patients with gastro-oesophageal reflux disease have delayed gastric emptying. This study investigates the effect of cisapride on gastric emptying in 34 patients with proved reflux and delayed gastric emptying of solids. They were enrolled in a double blind controlled crossover study. Placebo or cisapride (10 mg) tablets were given three times a day for three days followed by further assessment of gastric emptying. The protocol was repeated with the crossover tablet. Gastric - emptying was assessed by a dual radionuclide technique. The percentage of a solid meal remaining in the stomach at 100 minutes ( $\% \mathbf{R}_{100}$ minutes) and the time taken for $50 \%$ of the liquid to empty ( $T_{50}$ minutes) were calculated and analysed by the Wilcoxon matched pairs signed ranks test and expressed as medians (ranges). For gastric emptying of solids the initial $\% \mathbf{R}_{100}$ minutes (70 $(60-100) \%)$ was not significantly different from placebo (71 (35-100)\%). After cisapride treatment a significant acceleration $(p<0.001)$ in gastric emptying occurred ( $\% \mathbf{R}_{100}$ minutes, $50.5(28-93) \%)$. Similarly with gastric emptying of liquids, the initial $T_{50}$ minute value was 26.5 (12-82) minutes, after placebo the value was 28 (11-81) minutes, but this was significantly accelerated with cisapride $(p<0.03)$ to $22.5(6$ 61) minutes. The acceleration in gastric emptying occurred in the proximal portion of the stomach for gastric emptying of both solids and liquids suggesting that this is the principal site of action of cisapride. We conclude that cisapride significantly accelerates gastric emptying of both solids and liquids in patients with gastro-oesophageal refiux disease and delayed gastric emptying.
\end{abstract}
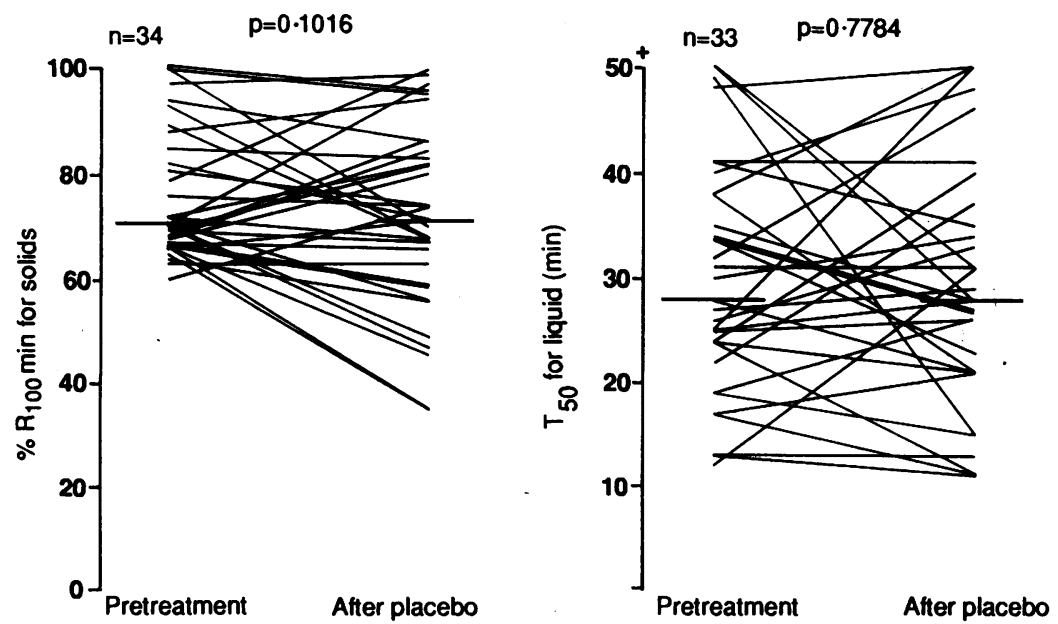

Figure 1: Solid (left) and liquid (right) gastric emptying from the total stomach before and after treatment with placebo. There is no significant difference between the groups. Short horizontal bars are median values. $T_{50}=$ time taken for half of liquid to empty. $\% R_{100} \min =\%$ of solid meal remaining at 100 minutes.
It is now established that some patients with gastro-oesophageal reflux disease have delayed gastric emptying of liquids or solids, or both. The relative proportions of patients with delayed emptying, however, and the importance of any delay remain controversial. ${ }^{1}$ Because gastric emptying is a complex process and many factors influence it, some of the differences that have been recorded are probably related to the different assessment techniques being used.

Cisapride is a prokinetic agent that has been shown to enhance gastric emptying in normal patients ${ }^{2}$ and in those with dyspepsia. ${ }^{3}$ The aim of this study was to assess the effect of cisapride on gastric emptying in patients with delayed gastric emptying and gastro-oesophageal reflux disease.

\section{Methods}

\section{PATIENTS}

The subjects were patients referred to our unit for the investigation of symptoms of gastrooesophageal reflux disease. Thirty four patients were enrolled in the trial. There were equal numbers of men and women (median age 51 years, range 18-81 years). Three of the patients had undergone previous gastro-oesophageal surgery but none was taking any medication known to alter gastric emptying or acid production. All patients entered in the study had been shown to have delayed solid gastric emptying according to criteria previously published ${ }^{4}-21$ patients had delay in solid emptying alone and 13 patients delay in both liquid and solid emptying. All patients gave informed consent and the study was approved by the Ethics Committee of the Royal Adelaide Hospital.

\section{ASSESSMENT OF REFLUX DISEASE}

All patients underwent oesophageal manometry with $\mathrm{pH}$ studies or $\mathbf{2 4}$ hour $\mathrm{pH}$ assessment, or both. In the absence of endoscopic evidence of oesophagitis, only those showing a $\mathrm{pH}$ of less than 4 for more than $7 \%$ of the 24 hour period were classified as suffering from unequivocal gastro-oesophageal reflux disease. ${ }^{5}$ Endoscopy was performed in 30 patients. Endoscopic appearances were graded according to the degree of oesophagitis as absent, mild, moderate, or severe. Patients with gastric or duodenal ulcers, achalasia, scleroderma, or diabetes were excluded from the study.

\section{MEASUREMENT AT GASTRIC EMPTYING}

This test simultaneously measures gastric emptying of a solid meal ( $100 \mathrm{~g}$ of cooked ground beef containing $1-1.5 \mathrm{mCi}$ of in vivo labelled ${ }^{99 \mathrm{~m}} \mathrm{Tc}$ 
sulphur colloid-chicken liver) and a liquid meal $(150 \mathrm{ml}$ of $10 \%$ dextrose in water labelled with $0.75-1.0 \mathrm{mCi}$ of ${ }^{113 \mathrm{~m}} \mathrm{In}$-diethylenetriamine pentaacetic acid). The details of the test have been documented previously. ${ }^{46}$ Several parameters were derived from the data in relation to solid and liquid emptying (expressed as a percentage of the total meal remaining within the stomach $v$ time). For the solid component of the meal these were the lag period before food left the stomach, the percentage remaining at 100 minutes $\left(\% R_{100}\right.$ minutes), and the linear emptying after the lag period. The $50 \%$ emptying time for the solid meal was not used because some patients did not reach $50 \%$ emptying during the study period of two hours. For the liquid component the time for $50 \%$ emptying $\left(\mathrm{T}_{50}\right.$ minutes) was obtained.

In 27 of the studies, analysis of the distribution of the meal within the stomach was undertaken. ${ }^{7}$ This was performed by dividing the gastric region into proximal and distal regions of interest. The proximal stomach was defined as that part which was filled by the initial solid meal bolus at the end of the meal. The region defined by this bolus was designated the proximal stomach and the remaining area the distal stomach.

From analysis of the proximal and distal regions of interest it was possible to determine the percentage of solid remaining in the proximal stomach at 55 minutes ( $\% R_{55}$ minutes), and the time taken until $90 \%$ of the maximum distal stomach counts were reached $\left(\mathrm{DT}_{90}\right)$. A measure of retention in the distal stomach was derived by subtracting the $\mathrm{DT}_{90}$ value from the total stomach lag period.' Proximal gastric liquid emptying was measured by taking the percentage of the liquid meal remaining in the proximal stomach at 20 minutes ( $\% \mathrm{R}_{20}$ minutes), and an identical set of measures to those used for solid emptying were taken for distal gastric retention of liquid (a liquid $\mathrm{DT}_{90}$ and liquid lag- $\mathrm{DT} \mathrm{T}_{90}$ ).

\section{SYMPTOMS}

Symptoms were recorded at the time of enrolment into the study using a symptom score to
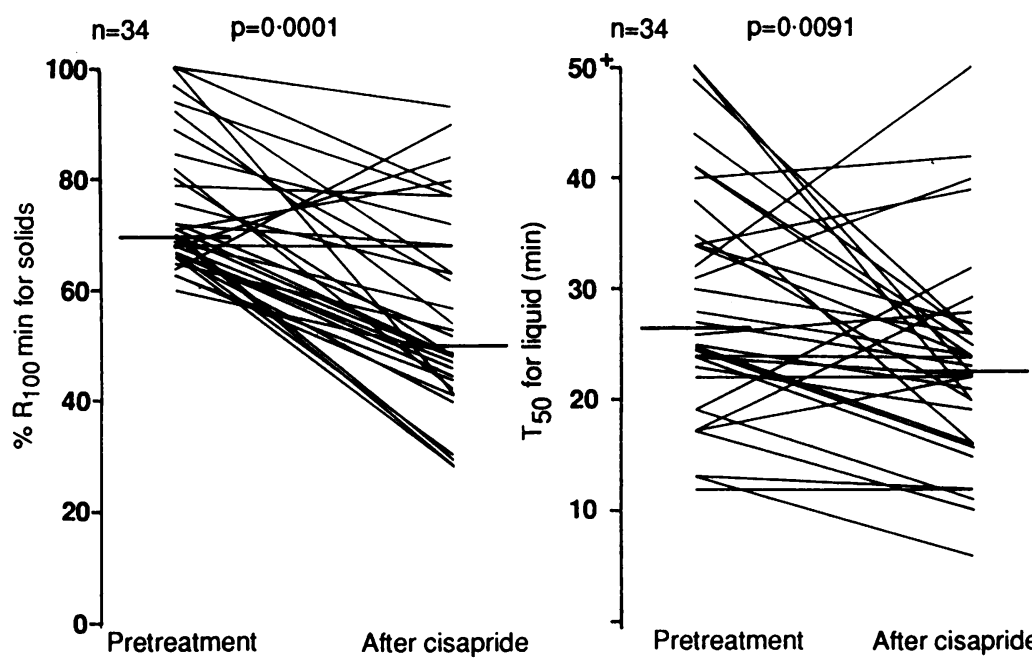

Figure 2: Solid (left) and liquid (right) gastric emptying from the total stomach before and after treatment with cisapride. Emptying was significantly faster after cisapride for both solids and liquids. Short horizontal bars are median values. $T_{\mathrm{su}}=$ time taken for half of liquid to empty. $\% R_{100}$ min $=\%$ of solid meal remaining at 100 minutes. assess severity. ${ }^{8}$ This assessment was applied to symptoms of regurgitation, heartburn, vomiting, nausea, dysphagia, epigastric fullness and also appetite, constipation, and diarrhoea. In addition antacid ingestion was recorded. These assessments were repeated before each subsequent gastric emptying test.

\section{STUDY DESIGN}

Medications known to affect gastric motility were stopped by the patient 48 hours before beginning the study. A double blind placebo controlled crossover design was used for the study with $10 \mathrm{mg}$ cisapride or placebo given three times a day for three days, with a week between each test period.

Placebo or cisapride was given one hour before breakfast and lunch and on going to bed at night. A further tablet - that is placebo or cisapride was taken one hour before a gastric emptying test that was undertaken at the end of the three day period. All patients kept a record of their symptoms and antacid ingestion during the treatment period. Patients were encouraged to report any untoward symptoms during the two study periods and they were also questioned directly about side effects at the time of the gastric emptying studies at the end of the three day period.

\section{STATISTICS}

Data were analysed using Wilcoxon matched pairs signed ranks test.

\section{Results}

MANOMETRY

Thirty patients underwent oesophageal manometry. The median (range) lower oesophageal sphincter pressure was $12(0-44) \mathrm{mmHg}$. Seventeen patients underwent 24 hour $\mathrm{pH}$ assessment and the median (range) percentage time of acid exposure was $15 \cdot 5(5 \cdot 6-79 \cdot 4) \%$. Endoscopic findings were available for 30 patients; 10 showed no evidence of oesophagitis, seven showed mild, five moderate, and eight severe oesophagitis.

\section{GASTRIC EMPTYING}

The $\% \mathbf{R}_{100}$ minutes solid meal emptying values were not significantly different between the pretreatment and placebo studies (Fig 1). These values were significantly less, however, in the cisapride treated group compared with either the placebo or the pretreatment groups $(p<0.0003$, $\mathrm{p}<0.0002$ respectively) (Figs 2 and 3 ). There were also significantly shorter lag periods $(p<0.001)$ for the cisapride group compared with the pretreatment or placebo groups (Table). Similarly, the rates of solid emptying after the lag period were more rapid $(p<0.001)$ in the cisapride group. The liquid emptying results showed a similar pattern (Figs 1, 2, and 3).

In three patients the proximal stomach region was not clearly enough defined to allow delineation of a proximal and distal region of interest. 

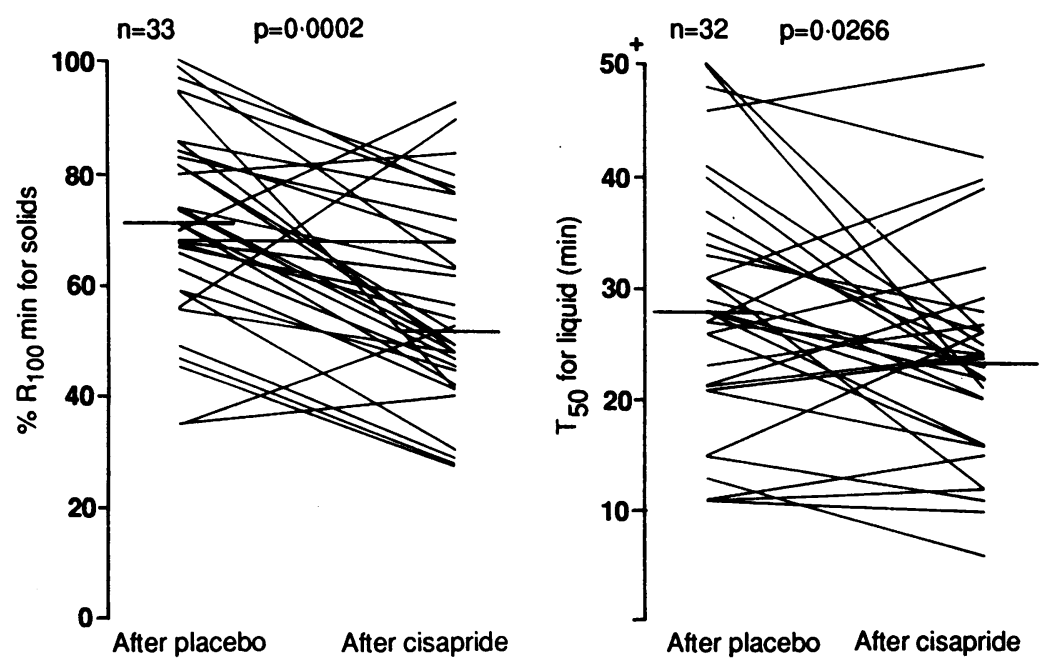

Figure 3: Comparison of solid (left) and liquid (right) gastric emptying from the total stomach after completion of the drug treatment - that is placebo or cisapride. Emptying was significantly faster after cisapride than after placebo for both solids and liquids. Shor horizontal bars are median values. $T_{50}=$ time taken for half of liquid to empty. $\% R_{100}$ min $=\%$ of solid meal remaining at 100 minutes.

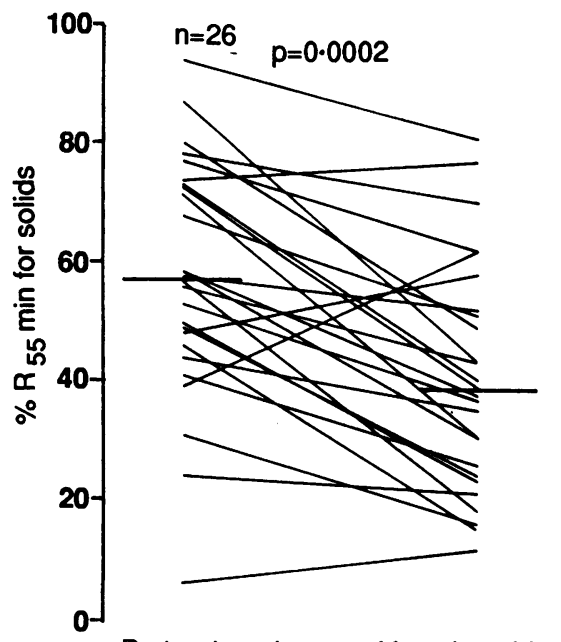

$n=24$

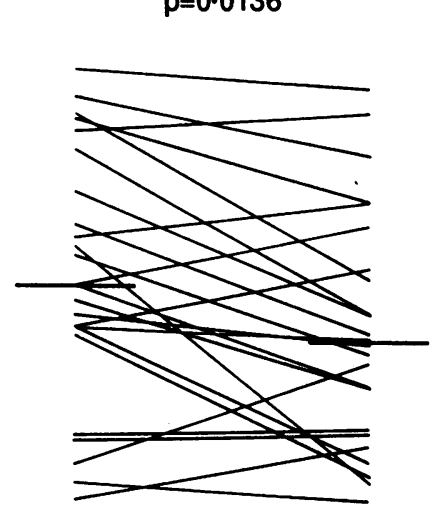

Pretreatment

After cisapride After placebo

After cisapride

Figure 4: Amount of a solid meal remaining in the proximal stomach at 55 minutes $\left(\% R_{5 s}\right.$ min) both before treatment and after cisapride (left), and cisapride compared with placebo (right). The amount remaining after cisapride is significantly less for both comparisons. Horizontal bars represent median values.
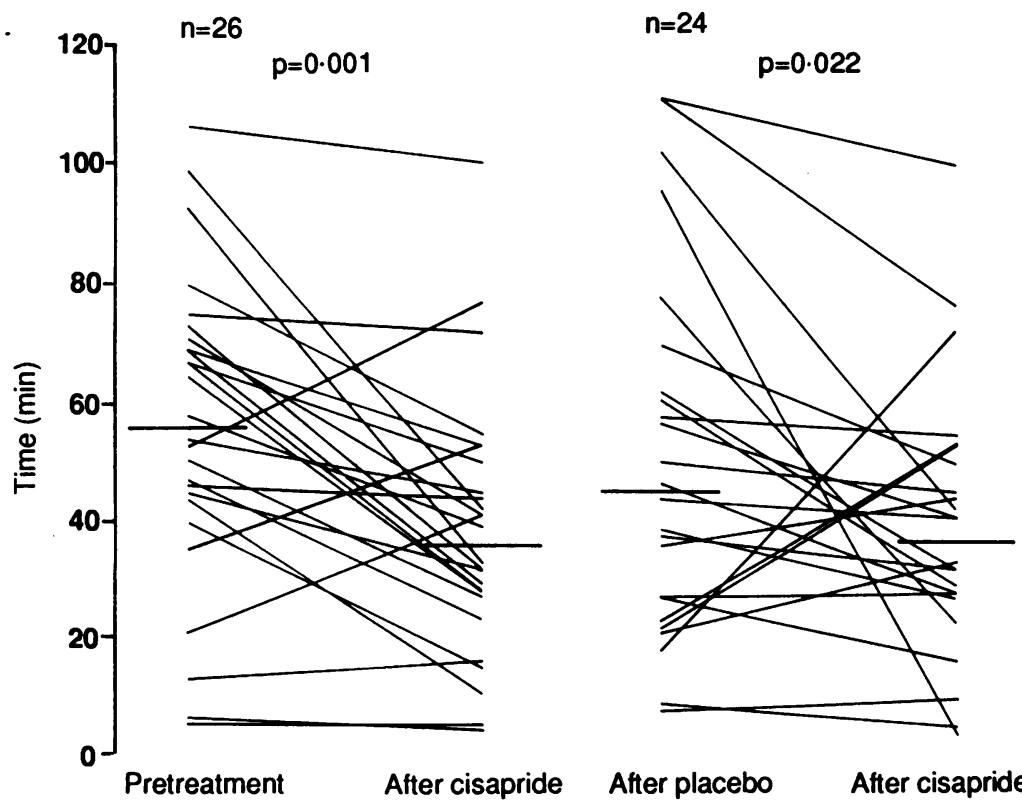

Figure 5: The time taken for a solid meal to reach $90 \%$ of the maximum distal stomach both before treatment and after cisapride (left) and cisapride compared with placebo (right). The time is significantly shorter after cisapride for both comparisons. Horizontal bars represent median values.
Emptying parameters for solid gastric emptying assessed before and after placebo or cisapride. Values are mean (range)

\begin{tabular}{llll}
\hline & Initial study & Placebo & Cisapride \\
\hline Lag (min) & $63(25-112)$ & $58(19-120)$ & $47(21-87)$ \\
$\begin{array}{l}\text { Rate }(\% / \\
\text { min) }\end{array}$ & $0.77(0.1-1 \cdot 5)$ & $0.71(0-1 \cdot 43)$ & $0.92(0 \cdot 45-1 \cdot 6)$ \\
$\begin{array}{c}\% \mathbf{R}_{100} \\
\text { mins }\end{array}$ & $70(60-100)$ & $71(35-100)$ & $50.5(28-93)$ \\
\hline
\end{tabular}

$\% R_{100}$ mins $=\%$ of meal remaining in stomach at 100 minutes.

Furthermore, as a result of misadventure in transferring data several other studies were lost after carrying out total emptying analysis. The gastric regions of interest were suitably defined to allow distributional analysis in 27 of the solid and liquid gastric emptying studies.

Gastric emptying times from the proximal stomach for solids, determined by the $\% \mathrm{R}_{55}$ minutes values, were significantly less in the cisapride group than in the pretrial $(p<0.0003)$ and placebo groups $(p<0.02)$ (Fig 4$)$. The $\mathrm{DT}_{90}$ values were also reduced in the cisapride group compared with placebo $(p<0.03)$ and pretreatment $(\mathrm{p}<0.002)$ results (Fig 5). The lag periods minus $\mathrm{DT}_{90}$ values, which are indicators of distal stomach retention, did not, however, show a significant difference between the cisapride and the placebo groups (Fig 6). Proximal liquid gastric emptyings ( $\% \mathbf{R}_{20}$ minutes) were enhanced in the cisapride group compared with placebo and pretreatment patients $(\mathrm{p}<0.05)$. As in the solid emptying studies, however, the liquid lag period minus the $\mathrm{DT}_{90}$ values were not smaller - that is there was no significant difference between groups with regard to the retention of liquid in the distal stomach.

\section{SYMPTOMS}

A significant improvement in symptom scores was recorded for dysphagia, regurgitation, and heartburn $(\mathrm{p}<0.01)$ after both placebo and cisapride, with cisapride also showing a significant lessening of a feeling of epigastric fullness $(\mathrm{p}<0.01)$.

There was no significant difference between the placebo and cisapride response and the remaining symptoms. No troublesome side effects were reported during the cisapride treatment period. There was no significant alteration in antacid ingestion between the placebo and cisapride period and bowel habit was not significantly altered, although four patients in the cisapride group complained of mild diarrhoea.

\section{Discussion}

When gastric emptying is assessed in patients with gastro-oesophageal reflux disease it seems that all groups find patients who have delayed emptying of solids. Some groups, however, have found no significant delay overall in emptying compared with control subjects, ${ }^{9-11}$ and some have found significant delay in patients compared with controls. ${ }^{612-17}$ Two groups have found that patients with delayed emptying are more likely to have endoscopically proved oesophagitis than patients with normal emptying, suggesting that the emptying problem may have a patho- 


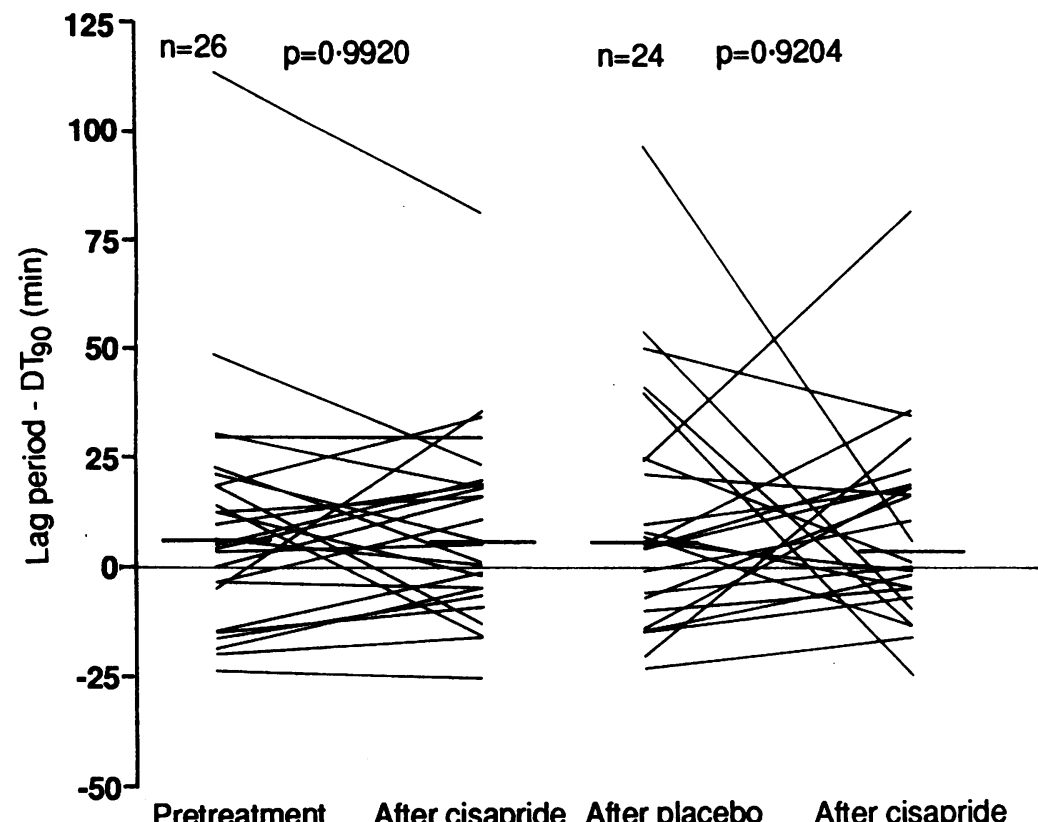

Figure 6: Lag periods minus time taken for $90 \%$ of distal stomach counts (lag-DT $T_{90}$ is a parameter which reflects the retention time of the solid meal in the distal stomach both before treatment compared with cisapride (left) and placebo compared with cisapride (right). There is no significant difference between the groups for either comparison. Horizontal bars represent median values. could effect these changes either by enhancing proximal gastric motor activity or by decreasing distal gastric retropulsion of food. Either or both of these mechanisms could have led to the results we obtained in these patients. Retropulsion was not observed, however, and so it seems more likely that cisapride had its effect on the proximal stomach.

On the other hand, the distal stomach does not seem to be emptying more rapidly once the bolus of food is delivered to it. If cisapride has led to an alteration in antral capacity, we are unsure how this would have affected our measurements. It could have led to an acceleration in gastric emptying but presumably would not have altered the redistribution time. Thus it seems more likely that the action of cisapride is on the proximal rather than the distal stomach in patients with gastro-oesophageal reflux and delayed gastric emptying.

It is of interest that the regulation of solid emptying from the stomach is often ascribed mainly to the antrum, although emptying is undoubtedly a complex process. ${ }^{26}$ Our results support the concept that the fundus and body of the stomach may play a more fundamental role in emptying of solids than is usually acknowledged. ${ }^{7}$ As was expected, both placebo and cisapride led to amelioration in patients' symptoms. ${ }^{24}$ Because of the short time course of treatment, however, symptomatic outcome was not a major aim of this study.

These results provide encouragement for further studies to determine if prolonged administration of cisapride to patients with gastro-oesophageal reflux disease and delayed gastric emptying will have a beneficial effect on the course of the disease.

This study was supported in part by a grant from Janssen-Cilag Pty Ltd.

1 Dubois A. Clinical relevance of gastro-duodenal dysfunction in reflux esophagitis. 7 Clin Gastroenterol 1986; 8: 17-25.

2 Lazzaroni M, Sangalotti O, Bianchi-Perro G. Effect of cisapride on gastric emptying and ileal transit time of balanced liquid meal in healthy subjects. Digestion 1987; 37: 110-3.

3 Urbaion JC, Siegel JO, Debie N, Pavwells JP. Effect of Cisapride on gastric emptying in dyspeptic patients. Dig Dis Sci 1988; 33: 779-83.

4 Collins PJ, Horowitz M, Cook DJ, Harding PE, Shearman DJC. Gastric emptying in normal subjects in a reproducible technique using a single scintillation camera and computer system. Gut 1983; 24:1117-25.

5 Jamieson GG, Duranceau AC. Staging of severity of gastroesophageal reflux. In: Jamieson GG, Duranceau AC, eds. esophageal reflux. In: Jamieson GG, Duranceau AC, eds. Gastro-esopl

6 Maddern GJ, Chatterton BE, Collins PJ, Horowitz M, Shearman DJC, Jamieson GG. Solid and liquid gastric emptying in patients with gastro-oesophageal reflux. Br $\mathcal{J}$ Surg 1985; 72: 344-7.

7 Collins PJ, Horowitz M, Chatterton BE. Proximal, distal and total stomach emptying of a digestible solid meal in normal subjects. Br $\mathcal{F}$ Radiol 1988; 61: 12-8.

8 Jamieson GG, Duranceau AC. Clinical features of gastroesophageal reflux disease. In: Jamieson GG, Duranceau A, eds. Gastro-esophageal reflux. Philadelphia: W B Saunders, 1988: 65-79.

9 Bost R, Hosditein G, Gignoux C, Busquet G, Lachet B Fournet J. Vidange gastrique d'un repas solide-liquide au cours du réflux gastro-oesophagien chéz' l'adulte. Gastrocours du reflux gastro-oesophagien

10 Johnson DA, Winters C, Drane WE, et al. Solid phase gastric emptying in patients with Barrett's oesophagus. Dig Dis Sci

11 Shaw SS, Eggli D, McDonald C, Johnson LF. Gastric emptying of solid food in patients with gastro-esophageal reflux. Gastroenterology 1987; 92: 459-65.

12 McCallum RW, Mensh R, Laing ER. Definition of the gastric emptying abnormality present in gastro-esophageal reflux patients. In: Weinbeck $M$, ed. Motility of the digestive tract. New York: Raven Press, 1982: 355-62. 
13 Collins BJ, McFarland RJ, O'Hare MMT, Shore C, Buchanan $\mathrm{KD}$, Love AHG. Gastric emptying of a solid-liquid meal and gastrointestinal hormone responses in patients with erosive oesophagitis. Digestion 1986; 33: 61-8.

14 Donovan IA, Harding LK, Keighley MR, Griffin DW, Collis JL. Abnormalities of gastric emptying and pyloric function JL. Abnormalities of gastric emptying and pyloric function in uncomplicated hiatus hernia. Br 7 Surg 1977; 64: 847-8.
5 Valenzuela JE, Cooley C, Anbsar IA, Miranda M, Samloff MI. Abnormal esophageal and gastric functions in patients with reflux esophagitis. Gastroenterology 1982; 82: 1201 .

16 Velasco N, Hill LD, Gannan RM, Pope CE. Gastric emptying and gastro-esophageal reflux: effects of surgery and correlation with esophageal motor function. Am f Surg 1982; 144: 58-62.

17 Little AG, DeMeester TR, Kirschner PT, O'Sullivan GC Skinner DB. Pathogenesis of esophagitis in patients with gastro-esophageal reflux. Surgery $1980 ; 88$ : $101-7$.

18 Myers JC, Collins PJ, Dehn TCB, Maddern GJ, Horowitz M, Jamieson GG. Which part of the stomach is responsible for delay in gastric emptying of solids in patients with gastrooesophageal reflux disease. $\mathcal{F}$ Gastroenterol Hepatol 1988; 3: oeso.

19 Behar J, Ramsby YG. Gastric emptying and antral motility in reflux esophagitis. Effect of oral metoclopramide. Gastro enterology 1978; 74: 253-6.
20 Fink SM, Barwick KW, Deluca E, Sanders FJ, McCallum RW. The association of histologic gastritis with gastroesophageal reflux and delayed gastric emptying. $\mathcal{F} \mathrm{Clin}$ esophageal reflux and delayed

21 Wattchow DA, Maddern GJ, Furness KB, Jamieson GG Distribution of peptide containing nerve fibres in the gastric muscularis externa of patients with gastro-esophageal reflux. Gastroenterology 1988; 94: 20 .

22 Holloway RH, Hongo M, Berger $\mathrm{K}$, McCallum RW. Gastric distention: a mechanism for post-prandial esophageal reflux. Gastroenterology 1985; 89: 779-84.

23 Dodds WJ, Dent J, Hogan WJ, et al. Mechanisms of gastroWith reflux esophagitis. $N E n g l$ f Med 1982; 307: 1547-52.

24 Maddern GJ, Kiroff GK, Leppard PI, Jamieson GG. Domperidone, metoclopramide and placebo. All give symptomatic improvement in gastroesophageal reflux. $\mathcal{f}$ Clin Gastroenterol 1986; 8: 135-40.

25 Collins BJ, Spence RAJ, Fergusson R, Laird J, Love AHG. Cisapride: influence on oesophageal and gastric emptying Cisapride: influence on oesophageal and gastric emptying and gastro-oesophageal reflux in patients with

26 Meyer JH. Motility of the stomach and gastroduodenal unction. In: Johnson LR, ed. Physiology of the gastrointest nal tract, 2nd ed. New York: Raven Press, 1987: 613-29. 